\title{
Pharmacological approaches to the management of type 2 diabetes in fasting adults during Ramadan
}

This article was published in the following Dove Press journal:

Diabetes, Metabolic Syndrome and Obesity: Targets and Therapy 28 April 2012

Number of times this article has been viewed

\author{
Mohamed A AIMaatouq \\ Endocrine Unit, Department \\ of Medicine, College of Medicine \\ and King Khalid University Hospital, \\ King Saud University, Riyadh, \\ Saudi Arabia
}

\begin{abstract}
More than 50 million Muslims throughout the world with type 2 diabetes mellitus (T2DM) fast for one lunar month (Ramadan) each year. Health care providers within and outside the Muslim world need to be aware of the nature of these partial days of fasting and their risks (and potential benefits) to people with T2DM, and need to provide Ramadan-adjusted diabetes care. Hypoglycemia during the fasting days represents the greatest health risk for these patients; hence, diabetes-related pharmacotherapy needs to be tailored and adjusted with this risk in mind. With limited trial data available, this review proposes practical modifications to the usual pre-Ramadan antidiabetic regimens that are based on pathophysiological principles, clinical trial evidence (where available), expert opinion, and extended practical experience. Individualization of care is paramount in this regard to take into consideration the patient and societal, cultural, and economic variables.
\end{abstract}

Keywords: type 2 diabetes mellitus, Ramadan, fasting, hypoglycemia, oral antidiabetic agents, insulin

\section{Introduction}

Followers of Islam accounted for nearly a quarter (1.7 billion) of the world's population (7 billion) in 2011. ${ }^{1}$ They inhabit the Middle East, North Africa, and central and east Asia. They also form a significant minority in almost every nation. ${ }^{2}$ Hence, health care issues peculiar to Muslims will inevitably be encountered worldwide, and health care providers and societies will have to deal with and accommodate their health needs.

Ramadan is the ninth month of the lunar calendar year. ${ }^{3}$ The lunar calendar is the focal point of religious activities, although the Gregorian calendar has been adopted (as in the rest of the globe) for business. Annual calendars that combine both the lunar and the Gregorian systems are available.

For all adults, fasting during the month of Ramadan on an annual basis (detailed below) is one of five pillars of Islamic practices, which also include the following: Shahadah, meaning faith in one God and faith in the prophet (Mohamed, and all other prophets); Salah, meaning five prayers a day; Zakah, meaning 2.5\% annual capital gain deduction, taken from the rich and given to the poor; Haj, meaning one pilgrim visit to Mecca in a lifetime, whenever possible; and Sawm, meaning Ramadan fasting, as discussed below. ${ }^{4}$

The fast includes abstinence from eating, drinking, and smoking only from sunrise to sunset. Thus, it represents only a partial day fast. The fasting hours vary from 10 hours in a temperate climate to 20 hours or more in hot climates, depending on the geographical location and time of Ramadan in the seasonal cycle. The lunar months
Correspondence: Mohamed A AIMaatouq Endocrine Unit, College of Medicine, King Saud University, PO Box 2925,

Riyadh I I46I, Saudi Arabia

Tel $+966 \mid 4671757$

Fax +966I4672423

Email mmaatouq@ksu.edu.sa 
shift by 13-15 days annually on the Gregorian calendar. The starting age of fasting varies between men and women according to the definitions of "responsible maturity" among the various religious schools within the Islamic faith. In general, girls start fasting earlier (at 9-12 years) than boys (at 13-15 years). Information related to fasting for Ramadan is shown in Figure 1.

Muslims are globally widespread. Some are privileged enough to have type 2 diabetes mellitus (T2DM) management that involves health care professionals who are aware of the fasting practice, adjustments to their therapeutic regimens to suit their clinical profiles, and provision of Ramadan-specific diabetes education. ${ }^{5}$ In contrast, patients in poor countries or deprived and remote communities face huge challenges related to the adequacy of and access to health care, availability of medications (especially insulin), and storage problems (given that off-grid communities often have no refrigeration facilities). This is in addition to high illiteracy rates and difficulties in providing the necessary Ramadan-focused diabetes education. These considerations and other relevant facts are detailed in this clinical review, which is aimed at practicing health care professionals caring for Muslims with T2DM who are intending to fast during the month of Ramadan.

\section{Methodology}

A Medline search for clinical trials that evaluated antidiabetic agents during Ramadan fasting in people with T2DM was undertaken. The following keywords were used: "type 2 diabetes mellitus", "Ramadan", "fasting", "oral antidiabetic agents", and "insulin". A total of 10 trials satisfied the criteria of a direct head-to-head comparison of two (or more) antidiabetic agents with preintervention-specified endpoints. Nine of the trials were prospective and controlled, and one was a retrospective audit. All were open-labeled and industrysponsored. These trials are described in a later section of this review. The conclusions drawn from these trials, in addition to expert opinions and published individual author opinions, support the synthesis presented in this review of the currently available literature pertinent to the management of adults with T2DM who intend to fast during the month of Ramadan.

\section{Metabolic adaptations to partial day fasting}

In otherwise healthy individuals without diabetes, glucose concentrations fall during fasting, which signals reduced insulin production by islet beta cells. This is coupled with enhanced production of glucagon by alpha cells and of catecholamines. ${ }^{6}$ These changes lead to an accelerated breakdown of glycogen stored in the liver. At an estimated rate of 8-10 grams of glycogen consumed per hour, hepatic glycogen stores (totaling 70 grams on average) are depleted within the first 10-12 hours of fasting. Antecedent with the enhanced glycogenolysis is augmented gluconeogenesis. Low levels of insulin also lead to increased fatty acid release from adipocytes. These fatty acids can be oxidized to generate ketones that are utilized as alternative fuels by all of the body organs, thus sparing glucose to be utilized by glucosedependent organs, ie, the brain and erythrocytes. ${ }^{7}$

This intricate balance between levels of circulating insulin and the counter-regulatory hormones, which maintain glucose

- Time: Days 1-29/30 of the lunar month. In 2012, this will be the July 15 to August 14 . Each year, Ramadan advances by 13-14 days on the Gregorian calendar. Ramadan will occur during the hot summer months over the next decade in most of the Muslim world.

- Duration: Fasting starts 75 minutes before sunrise and ends 15 minutes after sunset (or immediately at sunset in some sects). This results in a fast for 11-12 hours in equatorial countries and 16-20 hours or more in countries away from the equator (eg, Scandinavia).

- Fasting day: Abstaining from all eating, drinking, and smoking. Ingestion of any material including medications orally or parenterally is also prohibited.

- Who fasts: All mature (religiously responsible) adults (females above 9 years and males above 15 years of age) participate in the fast.

- Exemptions: Those who are ill (if fasting is expected to inflict significant harm), travelers, and menstruating females are exempted from the fast.

- Food consumption: Usually, two main meals are taken. One meal is at sunset (Iftar), which is usually communal (gatherings at mosques, clubs, streets, or family) with calorie-dense foods. The second meal is 2 hours before sunrise (Suhur), which is composed of slowly absorbed foods, such as beans, to sustain the individual during the long fasting hours of the day. Snacks are usually consumed between these meals. These patterns are variable among different cultures.

- Work, school, and leisure activities: In some (but certainly not all) predominantly Muslim countries, work and school hours are shortened to 5-6 hours. Nights are usually spent socializing, entertaining, and praying. The hours of the day are split between sleeping and working or attending school. Sports and physical activity are usually carried out in the evenings. Many Muslim countries and certainly all non-Muslim countries, however have no such allowances for Ramadan-related practices, and life proceeds as usual. The month of Ramadan is viewed as a month of celebration, sharing, giving, and soul searching. It is an opportunity to be close to God, society, family, and self.

Figure I Fact sheet on the fasting month of Ramadan. 
levels within a physiological range, is disturbed in people with T2DM. This is due to pathophysiological derangements in both insulin secretion and sensitivity, depending on the stage of the disease. Initially insulin insensitivity is predominant, with a resultant compensatory hyperinsulinemia but maintaining relative functional hypoinsulinemia. ${ }^{8}$ With progressive beta cell decline, there is continuing insulin deficiency, with eventual insulin depletion in the latter stages of the disease. Insulin sensitivity and/or secretion are also influenced by the pharmacological agents used in management of T2DM. Insulin therapy augments fasting hypoglycemia, while counterregulatory responses might be curtailed in the advanced stages, leading to profound and prolonged hypoglycemia. ${ }^{9}$

\section{Risks of fasting in people with T2DM Hypoglycemia}

As discussed above, fasting leads to reduced glucose levels that invoke compensatory mechanisms to prevent hypoglycemia. However, in the presence of certain antidiabetic agents that promote insulin secretion, or more commonly with insulin provision therapy, hypoglycemia may ensue, with potentially serious or even life-threatening consequences. ${ }^{10}$ In nonfasting people with T2DM, rates of hypoglycemia and related deaths are perceived to be lower (percentage unknown) than those encountered by people with T1DM (2\%-4\% mortality). ${ }^{11}$ In people with T2DM, the recent EPIDIAR (Epidemiology of diabetes and Ramadan 1422/2001) audit study showed that fasting during Ramadan increased the risk of severe hypoglycemia requiring hospitalization by sevenfold (from 0.4 to 3 events per 100 people per month). ${ }^{12}$ This is expected to be an underestimate if significant hypoglycemia requiring third party assistance is included in the analysis. Predictors of an increased frequency of severe hypoglycemia were medication (insulin or oral hypoglycemic agents) dose changes and drastic changes in lifestyle during Ramadan. In another recent five-country observational study, the incidence of hypoglycemia was $20 \%$ in sulfonylurea-treated patients who were fasting for Ramadan (range 14\%-26\%). ${ }^{13}$ These points are pivotal for the management of people with T2DM who are fasting for Ramadan, and need to be addressed when reviewing and adjusting their antidiabetic therapy.

\section{Hyperglycemia}

The link between glycemia and future long-term complications (both microvascular and macrovascular) in T2DM was well established by the UK Prospective Diabetes Study. ${ }^{8}$ However, short-term (eg, 4-week duration) hyperglycemia was not established as a contributor to long-term morbidity or mortality. It is still prudent to aim to avoid overt and/or symptomatic hyperglycemia during Ramadan to prevent its catabolic effects and the annoying accompanying features of polyuria, polydipsia, polyphagia, and visual disturbances. In the abovementioned EPIDIAR study, ${ }^{12}$ the incidence of severe hyperglycemia requiring hospitalization increased by five-fold (from 1 to 5 events per 100 people per month). Excessive food intake during the nonfasting eight hours (note that most patients actually gain weight during Ramadan $)^{13}$ and reductions in the dosages of antidiabetic agents (to avoid daytime fasting hypoglycemia) may contribute to the increased incidence of hyperglycemia by several-fold. Glycemic control has been reported to improve, remain unchanged, and even deteriorate during Ramadan fasting in people with T2DM. ${ }^{14-16}$

\section{Hypovolemia and thrombosis}

Prohibition of fluid intake during the fast is a potential cause of volume depletion, especially if the fasting is prolonged, and would be exacerbated by a hot climate and strenuous physical activity. Osmotic diuresis, which is a result of hyperglycemia, worsens the volume deficit and leads to a loss of electrolytes. ${ }^{17}$ The ensuing hypovolemia leads to orthostatic hypotension, which is worsened by pre-existing autonomic neuropathy, that brings about syncope, falls, and injuries, with potential fractures and wounds. ${ }^{18}$ The hypercoagulable state of diabetes is made worse by contraction of the intravascular space that in turn enhances blood viscosity. These derangements contribute to the increased risk of thrombosis and stroke. ${ }^{19}$ Hyperosmolar states can be predicted to occur in elderly patients with underlying comorbidities, especially those with poor dietary intake or superadded infections (particularly urinary tract, pneumonia, and skin wounds) in the absence of adequate health care. However, there are no data on mortality due to fasting in people with T2DM.

\section{Management of T2DM during Ramadan fasting Goals}

The overriding consideration for the management of patients with T2DM during the fasting month of Ramadan is patient safety. Effort has been focused on avoidance of acute metabolic derangements, including hypoglycemia, overt/symptomatic hyperglycemia, hyperosmolar states, hypovolemia, and heat exhaustion (in hot climates, especially with strenuous physical activity). Diabetic ketoacidosis is rarely encountered in people with T2DM, unlike those with T1DM. 
Although all of the effort should be expended to achieve a stable glycemic state, an insistence on tight glycemic control is not warranted and may only exacerbate (and even induce) the abovementioned potential risks that are associated with fasting. Individualized, patient-tailored advice should be based on the best available evidence-based practices. This should be backed by clinical judgment and take into consideration the patient's clinical profile, available health care resources, socioeconomic variables, and cultural and religious beliefs and practices. Steps towards attainment of therapeutic goals and targets in people with T2DM and for helping patients with tools for better adherence to and compliance with therapeutic regimens have recently been proposed. These are mostly derived from clinical commonsense but are also supported by recently reported trial evidence. ${ }^{20}$ These general principles are also applicable to the management of people with T2DM during Ramadan fasting. ${ }^{21-23}$ Figure 2 proposes steps toward improving the management of people with T2DM who are fasting for Ramadan. Figure 3 depicts an algorithm for suggested adjustments to pre-Ramadan therapeutic regimens. ${ }^{24}$

\section{Ramadan-focused diabetes education for people with T2DM}

A recent UK study showed that rates of baseline hypoglycemic events were reduced by attending a structured Ramadan-focused diabetes education program designed for people with T2DM $(\mathrm{n}=57$ ) by approximately $50 \%$ (from 9 events at baseline to 5 events at the end of Ramadan), while the rates increased four-fold in the group that did not attend the program ( $\mathrm{n}=54$, from 9 events at baseline to 36 events by the end of Ramadan). ${ }^{25}$

Educational sessions can be provided by health care professionals to people with $\mathrm{T} 2 \mathrm{DM}$ who are intending to

- Provision of Ramadan-specific diabetes education (both health care providers and patients, their families, and concerned organizations)

- Pre-Ramadan review of patient's clinical profile including glycemic control and diabetes-unrelated comorbidities

- Making necessary Ramadan-specific therapeutic adjustments, as detailed in the text and summarized in Figure 3 and Tables 1 and 2

- Provision of continuing care before, during and after Ramadan, including home glucose monitoring and ensuring access and availability of medications.

Figure 2 Proposed steps for glycemic control during Ramadan fasting in people with type 2 diabetes mellitus. fast for Ramadan individually or in groups, and preferably several weeks before Ramadan to provide adequate time for the patients and their families or caregivers to prepare for the fasting month. In underprivileged communities, public places (schools, mosques, public gatherings, and charities) can be used for both education and providing resources, including medications, glucose monitoring, and food packages, which is befitting of the spirituality and atmosphere of giving and sharing of the holy month. Sessions should include advice on the following:

- Risks of fasting

- Meal planning and food choices to avoid post-Iftar (sunset meal) hyperglycemia and fasting day hypoglycemia

- Timing and dosing of medications

- Physical activity during both the fed and fasting states (especially for strenuous jobs, hot climates, and prolonged fasting hours)

- Home capillary glucose monitoring

- Response to hyperglycemia

- Response to fasting hypoglycemia and when to break the fast. In general, patients are advised to break the fast if their blood glucose is less than $70 \mathrm{mg} / \mathrm{dL}$ $(3.9 \mathrm{mmol} / \mathrm{L})$ in the early fasting hours because hypoglycemia can only worsen, especially in patients taking insulin and/or sulfonylureas. The fast should also be terminated if the blood glucose is less than $60 \mathrm{mg} \%$ $(3.3 \mathrm{mmol} / \mathrm{L})$ at any time of the day. No such limits are established for hyperglycemia because patients may remain asymptomatic in the face of markedly elevated glucose concentrations.

\section{Pharmacotherapy for glycemia in fasting people with T2DM}

Based on the pathophysiological understanding of the progressive nature of T2DM from a predominance of insulin resistance, which is reflected in fasting euglycemia and postprandial hyperglycemia, insulin sensitizers (metformin and glitazones) are viewed as baseline therapies at this stage of the disease. ${ }^{26}$ Alpha-glucosidase inhibitors are also used at this stage, but to a lesser extent. This is due in part to their limited efficacy (average glycosylated hemoglobin $\left[\mathrm{HbA}_{1 \mathrm{c}}\right]$ reduction $0.5 \%$ ) and, to a larger extent, their gastrointestinal side effects, namely flatulence. ${ }^{27}$ With a progressive islet beta cell decline, which is evidenced by fasting hyperglycemia and worsening postprandial glucose excursions, the insulin secretagogues (glinides and sulfonylureas) are introduced. ${ }^{28}$ This is eventually followed by the need for insulin provision therapy for what is termed the "secondary 


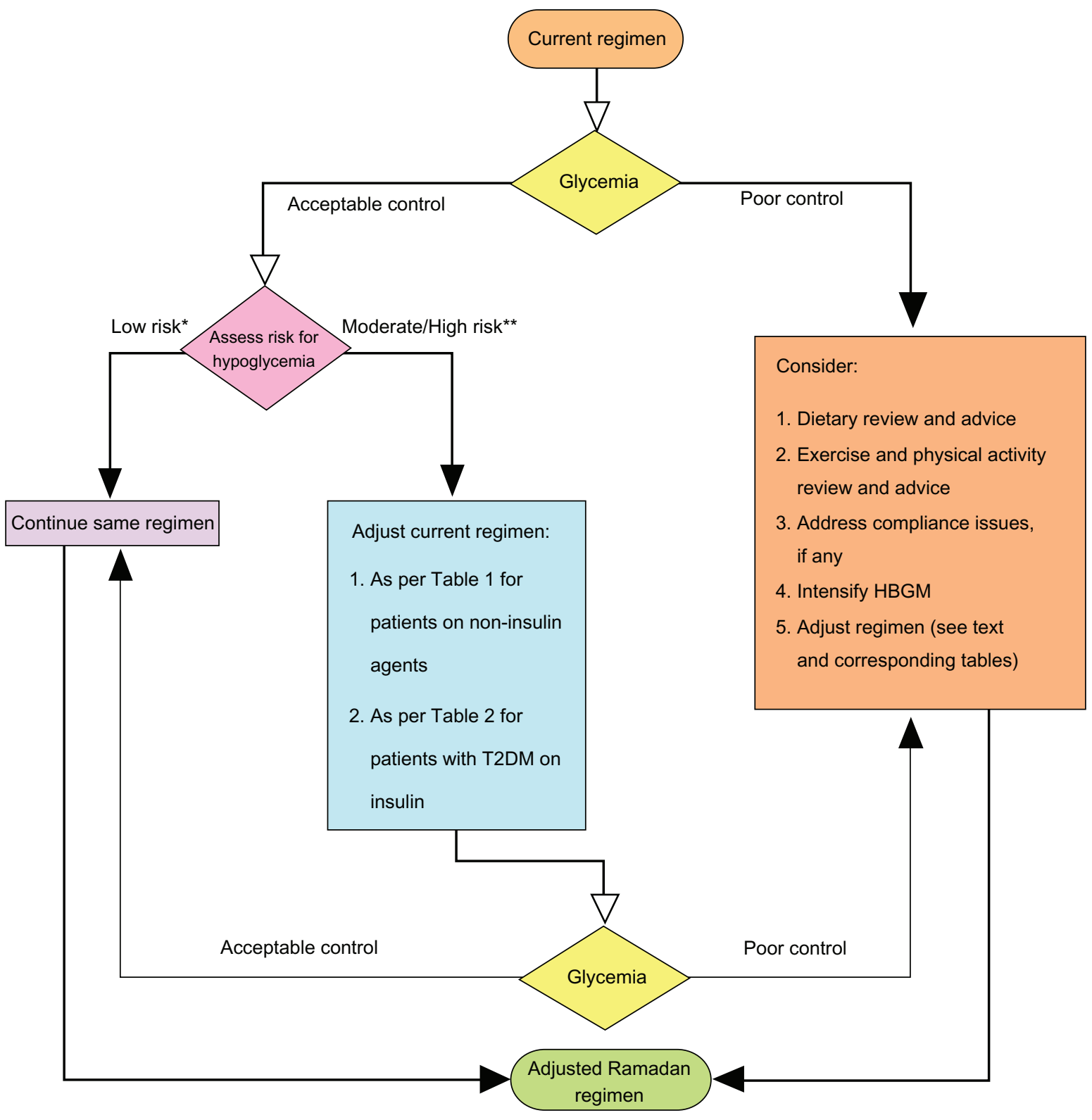

Figure 3 Proposed algorithm for pre-Ramadan review and adjustments of lifestyle and therapeutic regimens.

Adapted and modified from AIMaatouq. ${ }^{24}$ *Stable glycemic control with no major comorbidities on metformin, glitazones, alpha glucosidase inhibitors and incretin modulators. **Fluctuating glycemia, major comorbidities esp. renal/hepatic insufficiency and/or use of insulin and sulfonylureas.

sulfonylurea failure" stage. ${ }^{29}$ Early insulin introduction in patients who initially present with marked and/or symptomatic hyperglycemia (islet beta cell rescue from glucotoxicity) has gained popularity. ${ }^{30}$ Figure 4 depicts principles for the judicial use of pharmacological antidiabetic agents during Ramadan fasting.

Early introduction of basal insulin, in addition to insulin sensitizers, has also been advocated in recent treatment guidelines as an alternative to the addition of sulfonylureas as a second-line strategy for the management of glycemia in T2DM. ${ }^{31}$ This is intensely debated, partly due to a lack of trial evidence on the end-organ benefit and mostly due to a reluctance to introduce insulin early on in a chronic disease. This reluctance is thought to be due to the significant impact on the patient's lifestyle and quality of life. ${ }^{32}$

The recent introduction of an incretin-based therapy and, to a lesser extent, amylin-based agents and sodium-glucose cotransporter 2 inhibitors, has added to the armamentarium of antidiabetic agents, especially in view of their weight gain-sparing effect and proclaimed ability to preserve islet beta cells. ${ }^{33-35}$ Figure 5 summarizes the mode and site of action of the commonly used antidiabetic agents in relation to their hypoglycemic risk and their weight gain-sparing potential. ${ }^{24}$ 
- Consider regimen adjustments in the pre-Ramadan period to avoid last-minute drastic changes that might not be efficacious or that might lead to unexpected side effects.

- Consider agents with the least potential for hypoglycemia (in the absence of contraindications, as detailed in the text and illustrated in Figure 5) wherever possible. These include the following:

- Insulin sensitizers (metformin, a biguanide, and pioglitazone, a thiazolidinedione)

- Incretin-based agents, such as the dipeptidylpeptidase-4 inhibitors and the glucagon-like peptide-1 mimetics

- Alpha-glucosidase inhibitors, such as acarbose and voglibose.

- These should be utilized as baseline agents. Consideration should be given to switching to these agents and/or adding them to the pre-existing regimen.

- Choose agents with complementary actions that are pathophysiologically based.

- Consider agents that can be used only once daily, eg, long-acting metformin preparations or pioglitazone, to improve compliance.

- A simpler regimen is better. Neutral protamine Hagedorn insulin in combination with metformin taken at Iftar might be just as efficacious and have a better adverse profile potential and improved compliance compared with more elaborate regimens.

- Specific noninsulin regimen adjustments are detailed in the text and summarized in Table 1.

- Specific insulin regimen adjustments are detailed in the text and summarized in Table 2.

- Consider readily available agents that are less costly as long as the efficacy and safety are ensured.

- Review regimen before, during, and after Ramadan and make necessary adjustments, see Figure 3.

Figure 4 Principles of antihyperglycemic therapeutic regimen adjustments in people with type 2 diabetes mellitus who are fasting for Ramadan.

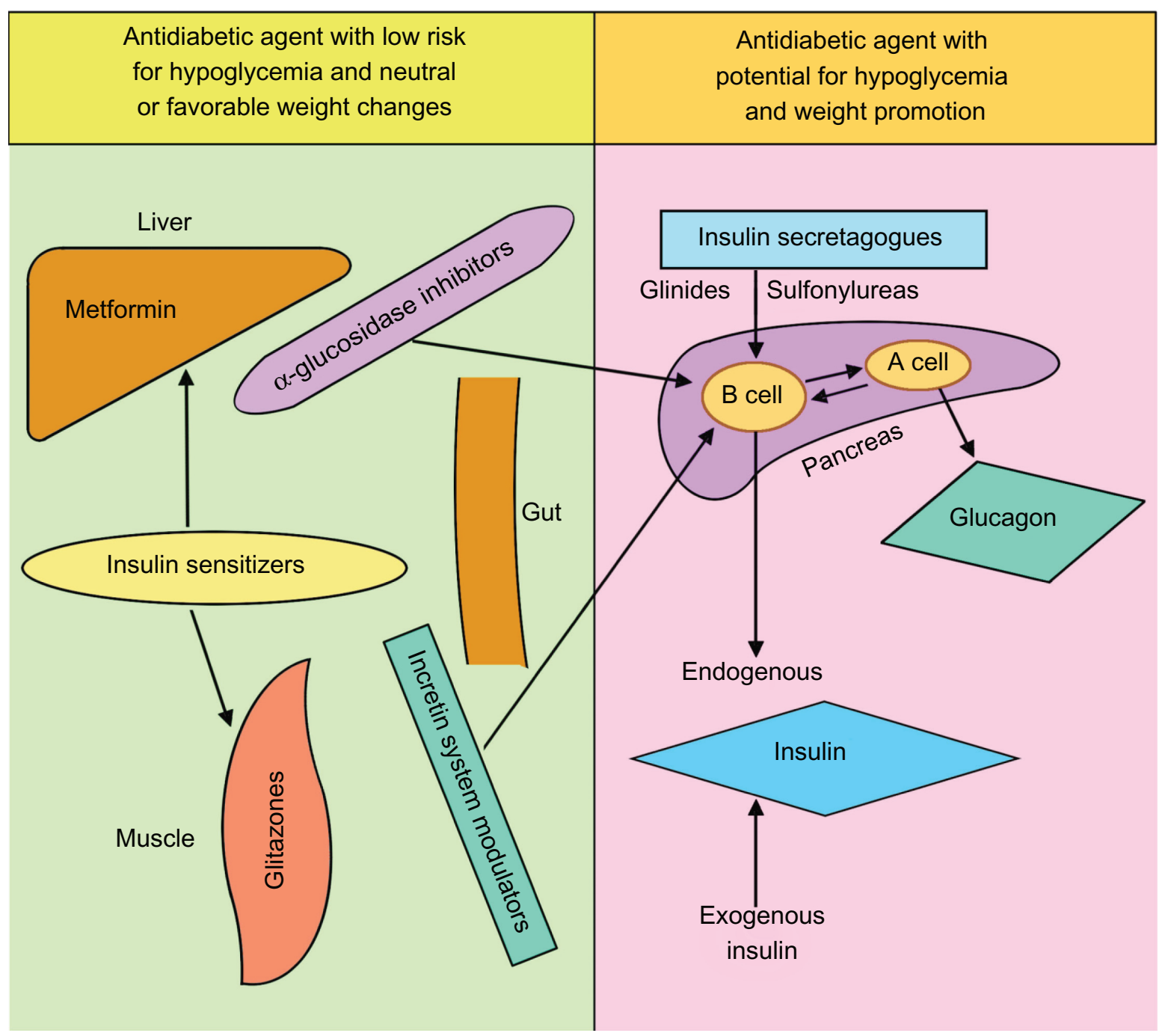

Figure 5 Site and mode of action of the most commonly used antidiabetic pharmacological agents, classified by their hypoglycemic risk potential and weight gain/loss characteristics.

Adapted and modified from AlMaatouq. ${ }^{24}$ 


\section{Adjustments of tools for glycemic control during Ramadan fasting Metformin}

Although the risk of severe hypoglycemia due to metformin in nonfasting patients is rare, ${ }^{36}$ there are no data on patients who are fasting for Ramadan and taking metformin. Because there are only two main meals in Ramadan, the metformin dose should be split into two thirds at Iftar and one third at Suhur. For example, for patients taking $850 \mathrm{mg}$ of metformin three times a day, their medication should be adjusted to $1700 \mathrm{mg}$ at Iftar and $850 \mathrm{mg}$ at Suhur. For patients on extended-release metformin preparations, the dose should be taken once at Iftar.

\section{Thiazolidinediones}

Pioglitazone is currently the only nonrestricted agent in use from this class due to the unfavorable safety profile of rosiglitazone. ${ }^{37}$ Hypoglycemia is not usually associated with this class of agents, but hypoglycemia due to other accompanying agents can be exacerbated. If pioglitazone is being considered as an addition to or a substitution of other agents in the pre-Ramadan review, then this needs to be done several weeks before Ramadan because 2-4 weeks are required for its antiglycemic action to take full effect. The full dose (the author uses a maximum dose of $30 \mathrm{mg}$ ) is given once daily at Iftar during Ramadan.

\section{Incretin-based therapy}

Recently introduced modulators of the incretin system include the dipeptidylpeptidase-4 inhibitors and the glucagon-like peptide receptor agonists. The dipeptidylpeptidase- 4 inhibitors include oral agents that are currently available in clinical practice, ie, sitagliptin, vildagliptin, alogliptin, and saxagliptin. These agents are not associated with hypoglycemia but may increase the hypoglycemic effect of other agents, such as sulfonylureas, glinides, and insulin. Vildagliptin + metformin was associated with less hypoglycemia than gliclazide + metformin in patients with T2DM during Ramadan in a retrospective data audit. ${ }^{38} \mathrm{~A}$ recent prospective study of more than 1000 patients with T2DM who fasted during Ramadan found that the risk of hypoglycemia associated with a vildagliptinbased regimen (vildagliptin $100 \mathrm{mg}$ once daily) was lower than that of a sulfonylurea-based regimen (both with and without metformin). ${ }^{39}$ The glucagon-like peptide receptor agonists (incretin mimetics) include the short-acting (half-life 2 hours) exenatide and once-daily liraglutide. Exenatide can be dosed before the two main meals and is not associated with significant effects on fasting glucose. Liraglutide is dosed once daily, irrespective of the timing of meals, and has significant antiglycemic effects with fasting. Both agents require dose titration over a period of 2-4 weeks for their maximum effects to be seen, and both induce nausea in over half of patients. ${ }^{40}$ Currently, no published studies have evaluated these agents during Ramadan.

\section{Alpha-glucosidase inhibitors}

Acarbose, voglibose, and miglitol retard glucose absorption (thus modifying insulin secretion) by inhibiting the action of intestinal brush border alpha-glucosidases. Although the risk of hypoglycemia is low with these agents, their use is limited in clinical practice due to the high frequency of gastrointestinal side effects, mainly flatulence, and their subdued reduction of $\mathrm{HbA}_{1 \mathrm{c}}(\geq 0.5 \%)$, which necessitates the addition of other antiglycemic agents. ${ }^{27}$ No clinical studies have evaluated this class of drugs during Ramadan. There is no need for dose titration, and it is advisable to take these agents during the first bite of each main meal.

\section{Short-acting insulin secretagogues and sulfonylureas}

Because of their ultrashort duration of action, the shortacting insulin secretagogues (glinides, ie, repaglinide and nateglinide) can be used before the main two meals in Ramadan. Repaglinide was found to cause less hypoglycemia (0.03 versus 0.05$)$ compared with glibenclamide in patients with T2DM who fasted during Ramadan. ${ }^{41}$ However, there was no difference in $\mathrm{HbA}_{1 \mathrm{c}}$ reduction, fructosamine levels, or weight change in another small study that compared repaglinide, glimepiride, and gliclazide, and there was only one documented hypoglycemic event in a patient on glimepiride. ${ }^{42}$

Due to their efficacy $\left(\mathrm{HA}_{1 \mathrm{c}}\right.$ reduction $>1 \%$ ), widespread use, extended global experience, low cost, and the absence of evidence for an adverse profile, sulfonylureas are commonly used as a second-line therapy after metformin..$^{43}$ The potential for hypoglycemia has been documented in many studies, but fasting during Ramadan has not been shown to exacerbate this in several studies. ${ }^{44,45}$

In general, it is recommended to give two thirds of the daily dose of sulfonylureas at Iftar and one third at Suhur. It is also recommended to avoid long-acting sulfonylureas, such as chlorpropamide and tolbutamide, to avoid protracted hypoglycemia in both fasting and nonfasting people with T2DM. No studies have been carried out on the recently introduced modified-release formulations, such as gliclazide modified release, during Ramadan. Table 1 summarizes the 
Table I Adjustments of noninsulin antidiabetic regimens in people with type 2 diabetes who are fasting for Ramadan

\begin{tabular}{|c|c|c|}
\hline Regimen & $\begin{array}{l}\text { Iftar (sunset) } \\
\text { meal }\end{array}$ & $\begin{array}{l}\text { Suhur (predawn) } \\
\text { meal }\end{array}$ \\
\hline Metformin & Two thirds of dose & One third of dose \\
\hline $\begin{array}{l}\text { Pioglitazone and } \\
\text { other glitazones }\end{array}$ & $\begin{array}{l}\text { Full dose with } \\
\text { no change }\end{array}$ & None \\
\hline $\begin{array}{l}\text { Acarbose and other } \\
\text { a-glucosidase inhibitors }\end{array}$ & Same dose & Same dose \\
\hline $\begin{array}{l}\text { Dipeptidylpeptidase-4 } \\
\text { inhibitors }\end{array}$ & Same dose & Same dose \\
\hline $\begin{array}{l}\text { GLP, glucagon-like } \\
\text { peptide-I receptor } \\
\text { agonists }\end{array}$ & $\begin{array}{l}\text { Exenatide: same dose } \\
\text { Liraglutide: full dose }\end{array}$ & $\begin{array}{l}\text { Exenatide: same dose } \\
\text { Liraglutide: none }\end{array}$ \\
\hline Glinides & Same dose & Same dose \\
\hline Sulfonylureas & $\begin{array}{l}\text { Glibenclamide: } \\
\text { same dose } \\
\text { Gliclazide: same dose }\end{array}$ & $\begin{array}{l}\text { Glibenclamide: half } \\
\text { dose or none } \\
\text { Gliclazide: same dose }\end{array}$ \\
\hline
\end{tabular}

proposed alterations in noninsulin antidiabetic agents during the fasting month of Ramadan.

\section{Insulin therapy}

Insulin therapy during Ramadan fasting represents a challenge to both patients with T2DM and health care providers alike due to the potential for significant hypoglycemia, albeit this is less frequent (and rarely life-threatening) than that encountered in patients with T1DM. ${ }^{6}$

If insulin is to be introduced, this should be done several months before Ramadan to allow time to titrate the type(s) of insulin, dosage, and timing, as guided by the patient's lifestyle, meal patterns, costs, and availability. ${ }^{24}$ In general, the simplest regimen to achieve good fasting glycemic control is recommended as a starting point. This could be achieved with nocturnal basal insulin (alone or in combination with an insulin sensitizer, such as metformin, an incretin modulator, or an alpha-glucosidase inhibitor). This can later be augmented with short-acting insulin to cover postprandial glycemic excursions.

Several approaches to insulin regimen adjustments during Ramadan fasting have been postulated in recent reviews, which were based primarily on expert opinion and occasionally on small clinical trials. Table 2 summarizes the suggested adjustments to insulin regimens (types and doses) during Ramadan fasting.

\section{Single basal insulin}

Patients are advised to reduce the single basal insulin dose (preferably taken at Iftar) empirically by $20 \%-30 \%$ to
Table 2 Insulin regimen adjustments in people with type 2 diabetes who are fasting for Ramadan

\begin{tabular}{|c|c|}
\hline Regimen & Suggested adjustments \\
\hline $\begin{array}{l}\text { Single basal } \\
\text { (or premixed) } \\
\text { insulin }\end{array}$ & $\begin{array}{l}\text { Take insulin before dinner (Iftar) } \\
\text { Empirical reduction of dose by } 30 \% \text { (if blood } \\
\text { glucose is well controlled pre-Ramadan) } \\
\text { Adjust dose as per home blood glucose } \\
\text { monitoring to avoid daytime (especially late } \\
\text { in the day/pre-lftar) hypoglycemia }\end{array}$ \\
\hline $\begin{array}{l}\text { Twice daily } \\
\text { premixed } \\
\text { (or basal) insulin }\end{array}$ & $\begin{array}{l}\text { Take the usual larger dose at lftar } \\
\text { Reduce the smaller dose (usually before dinner) } \\
\text { by } 30 \% \text { to coincide with pre-Suhur/early } \\
\text { morning meal } \\
\text { Adjust doses to avoid early morning and } \\
\text { pre-sunset hypoglycemia }\end{array}$ \\
\hline $\begin{array}{l}\text { Twice daily premixed } \\
\text { insulin plus bolus } \\
\text { insulin before lunch }\end{array}$ & $\begin{array}{l}\text { Take the usual larger dose at Iftar } \\
\text { Omit the bolus dose unless the patient's eating } \\
\text { profile includes a large meal at midnight }\end{array}$ \\
\hline & $\begin{array}{l}\text { Basal insulin to be taken pre-lftar without dose } \\
\text { change } \\
\text { Bolus dose taken before Iftar may need to be } \\
\text { augmented } \\
\text { Bolus dose taken before Suhur is either } \\
\text { omitted or reduced to avoid daytime } \\
\text { hypoglycemia }\end{array}$ \\
\hline Premeal boluses & $\begin{array}{l}\text { Adjust the pre-Iftar dose to avoid postprandial } \\
\text { hyperglycemia } \\
\text { Adjust the pre-Suhur dose to avoid daytime } \\
\text { hypoglycemia }\end{array}$ \\
\hline
\end{tabular}

avoid daytime hypoglycemia, especially if the insulin is in combination with glinides or sulfonylureas. The dose can later be adjusted during Ramadan depending on the daytime fasting glycemia profile. A multicenter, observational, prospective study in fasting patients on metformin in combination with glimepiride before Iftar $(n=21)$, repaglinide given with both meals, or glargine given at $10 \mathrm{pm}$, showed a nonsignificant increase in rates of hypoglycemia for the glimepiride group (14.3\%). ${ }^{46}$ In nonfasting patients, several studies failed to show significant advantages in glycemic control $\left(\mathrm{HgA}_{1 \mathrm{c}}\right)$ or the rates of hypoglycemia when nonanalog insulin preparations (neutral protamine Hagedorn, Humulin N; Eli Lilly; Indianapolis, IN) were compared with the recently introduced and more costly analog preparations (glargine and detemir) when used in combination with oral agents. ${ }^{47,48} \mathrm{How}-$ ever, no similar studies have been carried out in people with T2DM who were fasting for Ramadan. Patients on a single premixed insulin regimen (alone or in combinations with oral agents) are advised to reduce their dose empirically by $20 \%-30 \%$, which should be taken before Iftar (evening meal). The dose can be adjusted according to post-Iftar glycemic excursions and fasting day glycemia levels. This regimen has 
the potential advantage of better post-Iftar glycemic control compared with a single long-acting or intermediate-acting basal preparation.

Twice-daily premixed (intermediate-acting) insulin Twice-daily premixed insulin is the most commonly used insulin regimen by people with T2DM in several countries, ${ }^{49}$ mostly due to patient convenience. Several studies have shown it to be just as efficacious in terms of glycemia control compared with more elaborate regimens, such as the more recently adopted basal-bolus regimen..$^{50,51}$

Patients are advised to take the larger premixed insulin dose at Iftar. This dose can be augmented to cover anticipated higher post-Iftar glucose excursions. The smaller dose is taken at Suhur, with empiric reduction of the dose by $20 \%-30 \%$. This should be adjusted during the month according to the daytime fasting glycemic levels. Whether the recently introduced and more costly analog mixed insulin preparations, eg, Humalog Mix 25 (25\% short-acting insulin lispro and $75 \%$ intermediate-acting neutral lispro protamine, Eli Lilly) or biphasic insulin aspart 30 (short-acting insulin aspart and $70 \%$ intermediate-acting aspart, Novo Nordisk) are significantly better in terms of both glycemic control and lower hypoglycemia rates than the nonanalog insulin preparations, eg, Humulin $\mathrm{M}_{3}$ (Eli Lilly, human insulin 30\% soluble, $70 \%$ isophane) and similar preparations from Novo Nordisk, sanofi-aventis, and other generic insulin preparation manufacturers, remains to be verified in the general nonfasting and fasting patient populations.

A randomized, open-labeled, crossover study compared the analog premixed insulin Humalog Mix 25 (Eli Lilly) with the nonanalog premixed insulin Humulin $\mathrm{M}_{3}$ (Eli Lilly), and, given in identical doses, the analog preparation showed somewhat better postprandial blood glucose control after Iftar and lower rates of hypoglycemic events. ${ }^{52}$ The use of a Humalog Mix 50 (50\% premixed lispro with 50\% neutral protamine lispro, Eli Lilly) preparation at Iftar and a nonanalog premixed 30:70 insulin preparation at Suhur (predawn meal) showed a modest reduction in postprandial glucose excursions and hypoglycemia rates compared with a twicenightly nonanalog premixed 30:70 insulin preparation. ${ }^{53}$

In the absence of clear and distinct advantages of the newer analog preparations, it is difficult to justify shifting patients from the well established, universally available, and cheaper nonanalog insulin preparations. However, adjustment of Iftar insulin doses to contain more short-acting insulin deserves consideration.

\section{Management of T2DM during Ramadan in underprivileged communities}

Most reviews of this topic have been directed towards the provision of diabetes care to people living in (or migrating to) socioeconomically advantaged societies. ${ }^{54-57}$ However, the fact remains that a significant majority of Muslims live in underprivileged societies with primitive or poorly structured health care and limited access and resources. Ramadan represents a challenge to people with T2DM (or any other illness or handicap) who wish to fast. At the same time, it is also an opportunity for society, governments, nongovernmental organizations, and charities to cooperate, consolidate, and coordinate resources to reach out and provide help, counseling, and supplies, including nutritional and medicinal.

Health care providers and patients can benefit from information on the use of low-cost medications, including generic oral antidiabetic agents, human nonanalog insulin, and point-of-care capillary glucose monitoring. These are just a few examples of low-cost alternatives that can help ensure that no-one is deprived of their basic health care needs. Prior studies have shown that the overwhelming majority of Muslims with T2DM will fast during Ramadan, irrespective of medical advice. ${ }^{12}$ No effort should be spared to assist all those who wish to fast from doing so as safely and courteously as possible.

\section{Limitations}

As discussed above, high-level evidence derived from randomized clinical trials evaluating currently available antidiabetic agents during Ramadan fasting are scarce. The available trial data are hence based on open-labeled studies of small sample size that are uniformly industry-sponsored. It follows that the opinions expressed in this review are of necessity based primarily on low-level trial evidence, published expert opinion, and anecdotal personal experience. The need for high-level evidence, based on high-quality clinical trials in this field, cannot be overemphasized.

\section{Conclusion}

The overwhelming majority of Muslims with T2DM will insist on fasting for Ramadan. Health care providers need to address the risks associated with partial day fasting and provide the best individually tailored approaches. This can be achieved with knowledge and skills based on pathophysiological principles, trial evidence, expert opinion, 
and experience. Success is more likely if the health care provider addresses and accommodates the personal health profile, cultural practices, and socioeconomic variables. Although hypoglycemia represents an imminent health risk, this can be minimized by structured Ramadan-focused diabetes education (for both the health care provider and patients) and medication adjustments (especially with respect to sulfonylureas and insulin). Similarly, drastic fluctuations in the glycemic profile (especially night-time hyperglycemia) can be avoided by appropriate pre-Ramadan assessment and counseling. Appropriate selection of tools for glycemic control until a steady glycemic state is achieved before Ramadan makes adjustments during fasting more efficacious. Safe fasting can be a reality with prudence and diligence by health care providers and can be facilitated by patient empowerment and support.

\section{Disclosure}

The author reports no conflicts of interest in this work.

\section{References}

1. Miller T, editor. Mapping the Global Muslim Population: A Report on the Size and Distribution of the World's Muslim Population. Washington, DC: Pew Research Center; 2009.

2. International Diabetes Federation. Diabetes Atlas 2011, 5th ed. Brussels, Belgium: International Diabetes Federation; 2011.

3. Sheikh Abdul Rauf. Muslim Way of Life. New Delhi, India: Taj Company; 1984.

4. Rashed AH. The fast of Ramadan. Br Med J. 1992;304:521-522.

5. Sheikh A, Gatrad AR. Caring for Muslim Patients. Oxford, UK: Radcliffe Medical Press; 2000.

6. Cryer PE, Davis SN, Shamoon H. Hypoglycemia in diabetes. Diabetes Care. 2003;26:1902-1912.

7. Cahill GF Jr. Starvation in man. N Engl J Med. 1970;282:668-675.

8. UK Prospective Diabetes Study Group. Intensive blood-glucose control with sulphonylureas or insulin compared with conventional treatment and risk of complications in patients with type 2 diabetes (UKPDS 33). Lancet. 1998;352:837-853.

9. Zammitt NN, Frier BM Hypoglycemia in type 2 diabetes: pathophysiology, frequency, and effects of different treatment modalities. Diabetes Care. 2005;12:2948-2961.

10. Bailey CJ, Day C. Hypoglycaemia: a limiting factor. Br J Diabetes VasC Dis. 2010;10:2-4.

11. Miller CD, Phillips LS, Ziemer DC, Gallina DL, Cook CB, El-Kebbi IM. Hypoglycemia in patients with type 2 diabetes. Arch Intern Med. 2001;161:1653-1659.

12. Salti I, Bénard E, Detournay B, et al; EPIDIAR study group. A population-based study of diabetes and its characteristics during the fasting month of Ramadan in 13 countries: results of the epidemiology of diabetes and Ramadan 1422/2001 (EPIDIAR) study. Diabetes Care. 2004;27:2306-2311.

13. Hajek P, Myers K, Dhanji AR, West O, McRobbie H. Weight change during and after Ramadan fasting. J Public Health (Oxf). November 13, 2011. [Epub ahead of print.]

14. Aravind SR, Tayeb K, Ismail SB, et al. Hypoglycemia in sulphonylurea-treated subjects with type 2 diabetes undergoing Ramadan fasting: a five-country observational study. Curr Med Res Opin. 2011;27:1237-1242.
15. Uysal AR, Erdogan MF, Sahin G, et al. Clinical and metabolic effects of fasting in 41 type 2 diabetic patients during Ramadan. Diabetes Care. 1998;21:2033-2034.

16. Laajam MA. Ramadan fasting and non-insulin-dependent diabetes: effect on metabolic control. East Afr Med J. 1990;67:732-736.

17. Belkhadir J, el-Ghomari H, Klocker N, et al. Muslims with noninsulin-dependent diabetes fasting during Ramadan: treatment with glibenclamide. Br Med J. 1993;307:292-295.

18. Katibi IA, Akande AA, Bojuwoye BJ, et al. Blood sugar control among fasting Muslims with type 2 diabetes mellitus in Ilorin. Niger J Med. 2001;10:132-134.

19. Akhan G, Kutluhan S, Koyuncuoglu HR. Is there any change in stroke incidence during Ramadan? Acta Neurol Scand. 2000;101:259-261.

20. Del Prato S, Felton A-M, Munro N, et al. Improving glucose management: ten steps to get more patients with type 2 diabetes to goal. Recommendations from the Global Partnership for Effective Diabetes Management. Int J Clin Pract. 2005;59:1345-1355.

21. Beshyah SA. Fasting during the month of Ramadan for people with diabetes: Medicine and Fiqh united at last. Ibnosina J Med Biomed Sci. 2009; 1:58-60.

22. National Institute for Clinical Excellence. Type 2 Diabetes: The Management of Type 2 Diabetes. Clinical Guideline 87. London, UK: National Institute for Clinical Excellence; 2009.

23. Mojaddidi M, Hassanein M, Malik R. Ramadan and diabetes: evidencebased guidelines. Prescriber. 2006;17:38-41.

24. AlMaatouq MA. Manual of Diabetes Practice. Milton Keynes, UK: AuthorHouse Publishing; 2010.

25. Bravis V, Hui E, Salih S, Mehar S, Hassanein M, Devendra D. Ramadan Education and Awareness in Diabetes (READ) program for Muslims with type 2 diabetes who fast during Ramadan. Diabet Med. 2010;27:327-331.

26. Turner RC, Cull CA, Frighi V, Holman RR. Glycemic control with diet, sulfonylurea, metformin, or insulin in patients with type 2 diabetes mellitus: progressive requirement for multiple therapies (UKPDS 49). JAMA. 1999;281:2005-2012.

27. Van de Laar FA, Lucassen PL, Akkermans RP, Van de Lisdonk EH, Rutten GE, Van Weel C. Alpha-glucosidase inhibitors for type 2 diabetes mellitus. Cochrane Database Syst Rev. 2005;2:CD003639.

28. Defronzo RA. Banting Lecture. From the triumvirate to the ominous octet: a new paradigm for the treatment of type 2 diabetes mellitus. Diabetes. 2009;58:773-795.

29. Del Prato S, Pulizzi N. The place of sulfonylureas in the therapy for type 2 diabetes mellitus. Metabolism. 2006;55 Suppl 1:S20-S27.

30. Mayfield JA, White RD. Insulin therapy for type 2 diabetes: rescue, augmentation and replacement of beta-cell function. Am Fam Physician. 2004;70:489-500.

31. Nathan DM, Buse JB, Davidson MB, et al. Management of hyperglycaemia in type 2 diabetes: a consensus algorithm for the initiation and adjustment of therapy: a consensus statement from the American Diabetes Association and the European Association for the Study of Diabetes. Diabetologia. 2004;49:1711-1721.

32. de Grauw WJ, van de Lisdonk EH, van Gerwen WH, van den Hoogen HJ, van Weel C. Insulin therapy in poorly controlled type 2 diabetic patients: does it affect quality of life? Br J Gen Pract. 2001; 51:527-532.

33. Drucker DJ, Nauck MA. The incretin system: glucagon-like peptide-1 receptor agonists and dipeptidylpeptidase-4 inhibitors in type 2 diabetes. Lancet. 2006;368:1696-1705.

34. Younk LM, Mikeladze M, Davis SN. Pramlintide and the treatment of diabetes: a review of the data since its introduction. Expert Opin Pharmacother. 2011;12:1439-1451.

35. Bailey CJ, Day C. SGLT2 inhibitors: glucuretic treatment for type 2 diabetes. Br J Diabetes Vasc Dis. 2010;10:193-199.

36. Bailey CJ, Turner RC. Metformin. N Engl J Med. 1996;334:574-579.

37. Retnakaran R, Zinman B. Thiazolidinediones and clinical outcomes in type 2 diabetes. Lancet. 2009;373:2088-2090. 
38. Devendra D, Gohel B, Bravis V, et al. Vildagliptin therapy and hypoglycemia in Muslim type 2 diabetes patients during Ramadan. Int J Clin Pract. 2009;63:1446-1450.

39. Al Sifri S, Basiounny A, Echtay A, et al. The incidence of hypoglycaemia in Muslim patients with type 2 diabetes treated with sitagliptin or a sulphonylurea during Ramadan: a randomised trial. Int J Clin Pract. 2011;65:1132-1140.

40. Buse JB, Rosenstock J, Sesti G, et al. Liraglutide once a day versus exenatide twice a day for type 2 diabetes: a 26-week randomised, parallel-group, multinational, open-label trial (LEAD-6). Lancet. 2009;374:39-47.

41. Mafauzy M. Repaglinide vs glibenclamide treatment of type 2 diabetes during Ramadan fasting. Diabetes Res Clin Pract. 2002;58:45-53.

42. Anwar A, Azmi KN, Hamidon BB, Khalid BA. An open-label comparative study of glimepiride versus repaglinide in type 2 diabetes mellitus Muslim subjects during the month of Ramadan. Med J Malaysia. 2006;61:28-35.

43. Belkhadir J, el Ghomari H, Klocker N, Mikou A, Nasciri M, Sabri M. Muslims with non-insulin dependent diabetes fasting during Ramadan: treatment with glibenclamide. Br Med J. 1993;307:292-295.

44. van Staa T, Abenhaim L, Monette J. Rates of hypoglycemia in users of sulfonylureas. J Clin Epidemiol. 1997;50:735-741.

45. Sari R, Balci MK, Akbas SH, Avci B. The effects of diet, sulfonylurea, and repaglinide therapy on clinical and metabolic parameters in type 2 diabetic patients during Ramadan. Endocr Res. 2004;30:169-177.

46. Cesur M, Corapcioglu D, Gursoy A, et al. A comparison of glycemic effects of glimepiride, repaglinide and insulin glargine in type 2 diabetes mellitus during Ramadan fasting. Diabetes Res Clin Pract. 2007;75:141-147.

47. Riddle MC, Rosenstock J, Gerich J. The treat-to-target trial: randomized addition of glargine or human NPH insulin to oral therapy of type 2 diabetic patients. Diabetes Care. 2003;26:3080-3086.
48. Haak T, Tiengo A, Draeger E, Suntum M, Waldha W. Lower withinsubject variability of fasting blood glucose and reduced weight gain with insulin detemir compared to NPH insulin in patients with type 2 diabetes. Diabetes Obes Metab. 2005;7:56-64.

49. Ilag LL, Kerr L, Malone JK, Tan MH. Prandial premixed insulin analogue regimens versus basal insulin analogue regimens in the management of type 2 diabetes: an evidence-based comparison. Clin Ther. 2007;29:1254-1270.

50. Janka HU, Plewe G, Riddle MC, Kliebe-Frisch C, Schweitzer MA, Yki-Jarvinen H. Comparison of basal insulin added to oral agents vs twice-daily premixed insulin as initial insulin therapy for type 2 diabetes. Diabetes Care. 2005;28:254-259.

51. Swinnen S, Hoekstra AJ, Devris H. Insulin therapy for type 2 diabetes. Diabetes Care. 2009;32 Suppl 2:S253-S259.

52. Mattoo V, Milicevic Z, Malone JK, et al; Ramadan Study Group. A comparison of insulin lispro mix 25 and human insulin 30/70 in the treatment of type 2 diabetes during Ramadan. Diabetes Res Clin Pract. 2003;59:137-143.

53. Hui E, Bravis V, Salih S, Hassanein M, Devendra D. Comparison of Humalog Mix 50 with human insulin mix 30 in type 2 diabetes patients during Ramadan. Int J Clin Pract. 2010;64:1095-1099.

54. Al-Arouj M, Assaad-Khalil S, Buse J, et al. Recommendations for management of diabetes during Ramadan: Update 2010. Diabetes Care. 2010;33:1895-1902.

55. Goenka N, Thomas S, Shaikh S, Morrisey J, Patel V. Providing diabetes care to Arab migrants in the UK: cultural and clinical aspects. $\mathrm{Br} J$ Diabetes Vasc Dis. 2007;7:283-286.

56. Karamat MA, Syed A, Hanif W. Review of diabetes management and guidelines during Ramadan. J R Soc Med. 2010;103:139-147.

57. Ahmed MH, Abdu TAM. Diabetes and Ramadan: an update on use of glycemic therapies during fasting. Ann Saudi Med. 2010;31:402-406.

\section{Publish your work in this journal}

Diabetes, Metabolic Syndrome and Obesity: Targets and Therapy is an international, peer-reviewed open-access journal committed to the rapid publication of the latest laboratory and clinical findings in the fields of diabetes, metabolic syndrome and obesity research. Original research, review, case reports, hypothesis formation, expert opinion and commentaries are all considered for publication. The manuscript management system is completely online and includes a very quick and fair peer-review system, which is all easy to use. Visit http://www.dovepress.com/testimonials.php to read real quotes from published authors. 